\title{
Effects of astigmatic keratotomy combined with scleral tunnel incisions for the treatment of high astigmatism after penetrating keratoplasty
}

\author{
ZHENG-YU GU, MIN-JIE YE, KANG-KANG JI and RONG-FENG LIAO \\ Department of Ophthalmology, The First Affiliated Hospital of Anhui Medical University, Hefei, Anhui 230022, P.R. China
}

Received April 12, 2018; Accepted October 3, 2018

DOI: $10.3892 /$ etm.2018.6968

\begin{abstract}
The present study aimed to evaluate the efficacy, predictability and safety of astigmatic keratotomy (AK) combined with scleral tunnel incisions in the treatment of high astigmatism after penetrating keratoplasty (PKP). Paired AK combined with scleral tunnel incisions was performed at the steep astigmatic meridian in 8 eyes of 8 patients with high keratometric astigmatism [ $>5.0$ diopters (D)] after PKP. Pre- and post-operative parameters, including uncorrected visual acuity (UCVA), best corrected visual acuity (BCVA), refraction and keratometric astigmatism were evaluated. The Alpins method for vector analysis was used to evaluate the changes in keratometric astigmatism. The results indicated a statistically significant reduction in the mean keratometric astigmatism from $8.16 \pm 3.02 \mathrm{D}$ pre-operatively to $2.28 \pm 1.07 \mathrm{D}$ at 3 months postoperatively. The mean UCVA improved from $0.95 \pm 0.24$ logarithm of the minimum angle of resolution ( $\log$ MAR) pre-operatively to $0.61 \pm 0.17 \log$ MAR at 3 months postoperatively $(\mathrm{P}<0.05)$. The mean BCVA improved from $0.41 \pm 0.18 \log$ MAR pre-operatively to $0.26 \pm 0.12 \log$ MAR at 3 months postoperatively $(\mathrm{P}>0.05)$. Between 3 and 6 months after the surgery, the keratometric astigmatism remained stable. Alpins vector analysis demonstrated the relative predictability of this combined surgical treatment. The surgically induced astigmatism was significantly correlated with the target induced astigmatism $(\mathrm{r}=0.76, \mathrm{P}<0.05)$. None of the patients had any severe complications. The present study indicated that $\mathrm{AK}$ combined with scleral tunnel incisions is an effective, relatively predictable and safe treatment for high astigmatism after PKP.
\end{abstract}

Correspondence to: Professor Rong-Feng Liao, Department of Ophthalmology, The First Affiliated Hospital of Anhui Medical University, 218 Jixi Road, Hefei, Anhui 230022, P.R. China E-mail: ayoph136@sina.com

Key words: high astigmatism, penetrating keratoplasty, astigmatic keratotomy, scleral tunnel incisions

\section{Introduction}

High astigmatism commonly occurs after penetrating keratoplasty (PKP). Due to the high residual astigmatism after PKP, patients often fail to obtain a satisfied visual acuity (1). In cases of high astigmatism, spectacles or contact lens correction may become difficult (2). Several surgical techniques to correct post-PKP astigmatism have been described. These include astigmatic keratotomy (AK) $(3,4)$, relaxing incisions $(5)$, corneal wedge resection (6), compression sutures (7), laser in situ keratomileusis (LASIK) (8) and implantation of toric intraocular lenses (IOL) (9). However, these methods have certain limitations. Compression sutures and LASIK are limited in the range of astigmatism they are able to correct. Toric IOL implantation is also limited by the range of the astigmatism correction (10) and not suitable for young patients without cataracts. With the emergence of femtosecond laser, the accuracy and safety of the treatment of corneal astigmatism has increased. The femtosecond laser has been successfully used in several corneal surgical procedures. Wang et al (11) investigated the efficacy of femtosecond laser-assisted cataract surgery combined with femtosecond laser AK to manage pre-operative astigmatism in cataract surgery and reported a significant decrease in astigmatism. Buzzonetti et al (12) used femtosecond laser-assisted AK to correct astigmatism after PKP and reported a decrease in astigmatism. In order to obtain an augmented effect for reducing high levels of corneal astigmatism after PKP, certain novel combined procedures have been designed. Çakır et al (13) used circular keratotomy combined with wedge resection to treat high astigmatism after PKP and reported a significant reduction in astigmatism. Sy et al (14) performed AK combined with conductive keratoplasty to treat high astigmatism after PKP and obtained a satisfactory reduction in astigmatism. AK involves placing 1 or 2 deep, arcuate corneal incisions perpendicular to the steep meridian of the astigmatism to flatten the steep corneal meridian. AK is conventionally used to correct moderate to high astigmatism (15). However, AK is also limited in the amount of astigmatism it is able to correct. Scleral tunnel incisions are able to flatten the corneal curvature when placed at the steepest astigmatism meridian. Weindler et al (16) performed a single 6-mm scleral tunnel incision to correct pre-operative astigmatism by placing the tunnel incision at the steep meridian during cataract surgery and reported a reduction in astigmatism from $1.60 \pm 0.65$ to $0.89 \pm 0.61 \mathrm{D}$. These changes in stromal architecture 
reduces astigmatism by placing incisions perpendicular to the steep axis of astigmatism to flatten the steep corneal meridian, and the combination of these two treatments is likely to produce a synergistic effect $(15,16)$.

To the best of our knowledge, no previous study has evaluated the effects of AK combined with scleral tunnel incisions to correct high astigmatism after PKP. The present study reported on the efficacy, predictability and safety of this combined surgical treatment.

\section{Patients and methods}

Patients. All surgeries were performed between January 2014 and March 2017 at the First Affiliated Hospital of Anhui Medical University (Hefei, China). This study was performed according to the tenets of the Declaration of Helsinki and was approved by the Ethics Committee of the First Affiliated Hospital of Anhui Medical University. Informed consent was obtained from all participants after explanation of the study and possible consequences. Inclusion criteria for the present study included, high post-PKP keratometric astigmatism $(>5.0 \mathrm{D})$, complete removal of sutures at least 6 months prior to the combined procedure and steady ametropia. Patients with regular astigmatism were included in the study, but highly irregular patterns of topographic astigmatism were excluded. General examinations were taken to exclude any systemic and other eye diseases. The TMS-4 topographic system (Tomey Corp., Nagoya, Japan) was used to measure the keratometric astigmatism. A total of 8 eyes of 8 patients with high residual keratometric astigmatism $(8.16 \pm 3.02 \mathrm{D})$ after PKP were enrolled in the present study.

Surgical procedure. Prior to the procedure, the corneal thickness was measured using a pachymetry map of the Angio optical coherence tomography (Angio-OCT) system (Optovue Corp., Fremont, CA, USA). Subsequent to topical anesthesia using $0.5 \%$ proparacaine hydrochloride (Alcaine; Alcon Laboratories, Inc., Fort Worth, TX, USA), the cornea was marked at the vertical meridian and the horizontal meridian pre-operatively in the sitting position to reduce the error induced by cyclotorsion in the lying position. The steep astigmatism meridian was marked intra-operatively according to the corneal topography obtained prior to surgery. A pair of symmetrical arc incisions were created along the steep meridian of the astigmatism using a guarded diamond blade. The length of the incisions was determined by the magnitude of the astigmatism and ranged from 60 to $85^{\circ}\left(60-65^{\circ}\right.$ for 5-6 $\mathrm{D}, 65-75^{\circ}$ for $7-10 \mathrm{D}$ and $85^{\circ}$ for $>10 \mathrm{D}$ of astigmatism). The incisions were placed $0.5 \mathrm{~mm}$ inside the graft-host junction at a depth of $~ 90 \%$ of the corneal thickness in all cases, and the anterior side-cut angle was set at $90^{\circ}$ to the corneal surface. Subsequently, the incisions were opened using a Sinskey and a pair of symmetrical scleral tunnel incisions were made $1.5 \mathrm{~mm}$ away from the cornea limbus at the steep astigmatic meridian using a scleral tunnel knife to make $6 \mathrm{~mm}$ wide incisions (Fig. 1). The area was then cleaned with balanced salt solution. All patients received the surgery from an experienced operator (RFL). Postoperatively, the operated eyes were treated with tobramycin and dexamethasone eye drops and levofloxacin eye drops 4 times daily for 2 weeks.

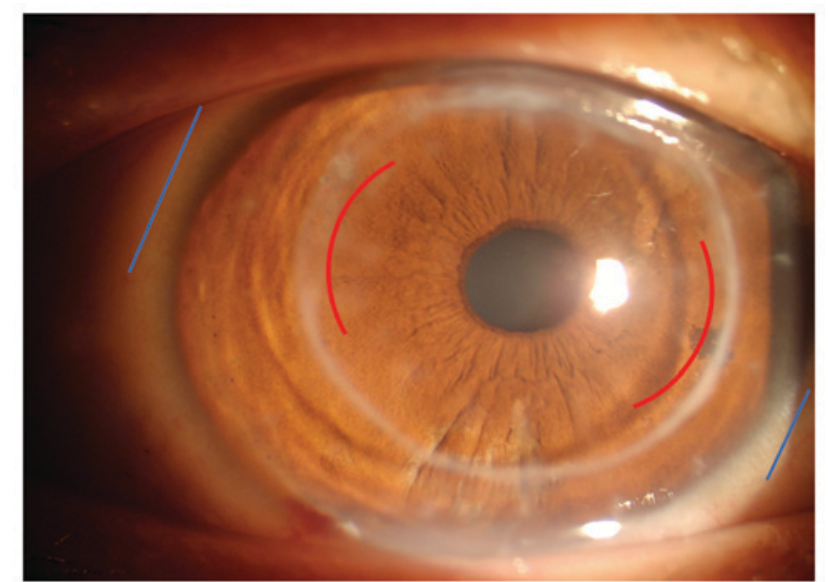

Figure 1. Representative case. AK combined with scleral tunnel incisions was performed on the right eye of a patient to correct the high astigmatism after penetrating keratoplasty. Diagrammatic drawing indicating paired AK (red arcs) and scleral tunnel incisions (blue straight line). AK, astigmatic keratotomy.

Patient assessment. Patients were regularly examined after the operation and the follow-up results at 3 and 6 months after the combined procedure were recorded. Pre- and post-operative evaluation included slit lamp examination, refraction, non-contact measurement of intraocular pressure, logarithm of the minimum angle of resolution (LogMAR) of uncorrected visual acuity (UCVA) and best corrected visual acuity (BCVA). Keratometric astigmatism was measured by corneal topography. Angio-OCT was used to obtain cross-sectional images of the corneal incisions and assess the wound healing of these corneal incisions.

Vector analysis. Keratometric astigmatism vectors were evaluated using the Alpins method, which assesses the effective change in keratometric astigmatism (17). Vector parameters analyzed included: The target induced astigmatism (TIA), defined as the astigmatic correction in magnitude and axis the operator intended to induce, which is equivalent to the pre-operative astigmatism; surgically induced astigmatism (SIA), defined as the amount and axis of astigmatic change actually induced by surgery; difference vector (DV), defined as the vector difference of TIA and SIA and reflecting the post-operative astigmatism; angle of error (AE), which is the angle offset between SIA and TIA-it is positive if SIA is on an axis counterclockwise to TIA and negative if SIA is on an axis clockwise to TIA; magnitude of the error (ME), which is the magnitude difference between SIA and TIA-it is positive for overcorrection and negative for undercorrection; correction index, calculated by dividing the SIA by the TIA-it is ideally 1.0 , and $>1.0$ for overcorrection and $<1.0$ for undercorrection; index of success (IOS), calculated by dividing the DV by the TIA-it is ideally 0 .

Statistical analysis. Statistical analysis was performed using SPSS software (version 17.0; SPSS, Inc., Chicago, IL, USA). Values are expressed as the mean \pm standard deviation. The paired Student t-test was used to assess the difference between pre-operative and post-operative values. Pearson correlation analysis was used to assess the correlation between SIA and TIA. P $<0.05$ was considered to indicate a statistically significant difference. 
Table I. Visual acuity and keratometric astigmatism at baseline and 3 months after surgery.

\begin{tabular}{|c|c|c|c|c|c|c|c|c|c|c|}
\hline \multirow[b]{2}{*}{ Case no. } & \multicolumn{2}{|c|}{ Characteristics } & \multicolumn{4}{|c|}{ Pre-operative } & \multicolumn{4}{|c|}{ Post-operative } \\
\hline & $\begin{array}{c}\text { Age } \\
\text { (years) }\end{array}$ & Sex & $\begin{array}{c}\text { UCVA } \\
(\text { LogMAR) }\end{array}$ & $\begin{array}{c}\text { BCVA } \\
\text { (LogMAR) }\end{array}$ & $\begin{array}{l}\text { KA } \\
\text { (D) }\end{array}$ & Axis $\left({ }^{\circ}\right)$ & $\begin{array}{c}\text { UCVA } \\
\text { (LogMAR) }\end{array}$ & $\begin{array}{c}\text { BCVA } \\
\text { (LogMAR) }\end{array}$ & $\begin{array}{l}\text { KA } \\
\text { (D) }\end{array}$ & Axis $\left({ }^{\circ}\right)$ \\
\hline 1 & 22 & Male & 1.30 & 0.60 & 9.29 & 159 & 0.50 & 0.20 & 1.23 & 73 \\
\hline 2 & 27 & Male & 1.00 & 0.40 & 7.38 & 170 & 0.80 & 0.40 & 3.42 & 166 \\
\hline 3 & 24 & Male & 0.80 & 0.30 & 10.78 & 87 & 0.40 & 0.20 & 2.07 & 15 \\
\hline 4 & 35 & Female & 0.70 & 0.40 & 5.63 & 76 & 0.50 & 0.20 & 2.29 & 166 \\
\hline 5 & 23 & Male & 0.80 & 0.20 & 7.65 & 149 & 0.60 & 0.20 & 2.18 & 118 \\
\hline 6 & 21 & Female & 1.00 & 0.70 & 5.70 & 127 & 0.90 & 0.40 & 2.13 & 117 \\
\hline 7 & 56 & Female & 1.30 & 0.50 & 13.89 & 34 & 0.70 & 0.40 & 4.12 & 24 \\
\hline 8 & 28 & Male & 0.70 & 0.20 & 5.02 & 100 & 0.50 & 0.10 & 0.83 & 129 \\
\hline Mean & 29.50 & & 0.95 & 0.41 & 8.17 & & 0.61 & 0.26 & 2.28 & \\
\hline SD & 11.60 & & 0.24 & 0.18 & 3.02 & & 0.17 & 0.12 & 1.07 & \\
\hline
\end{tabular}

UCVA, uncorrected visual acuity; BCVA, best corrected visual acuity; KA, keratometric astigmatism; D, diopters; SD, standard deviation.
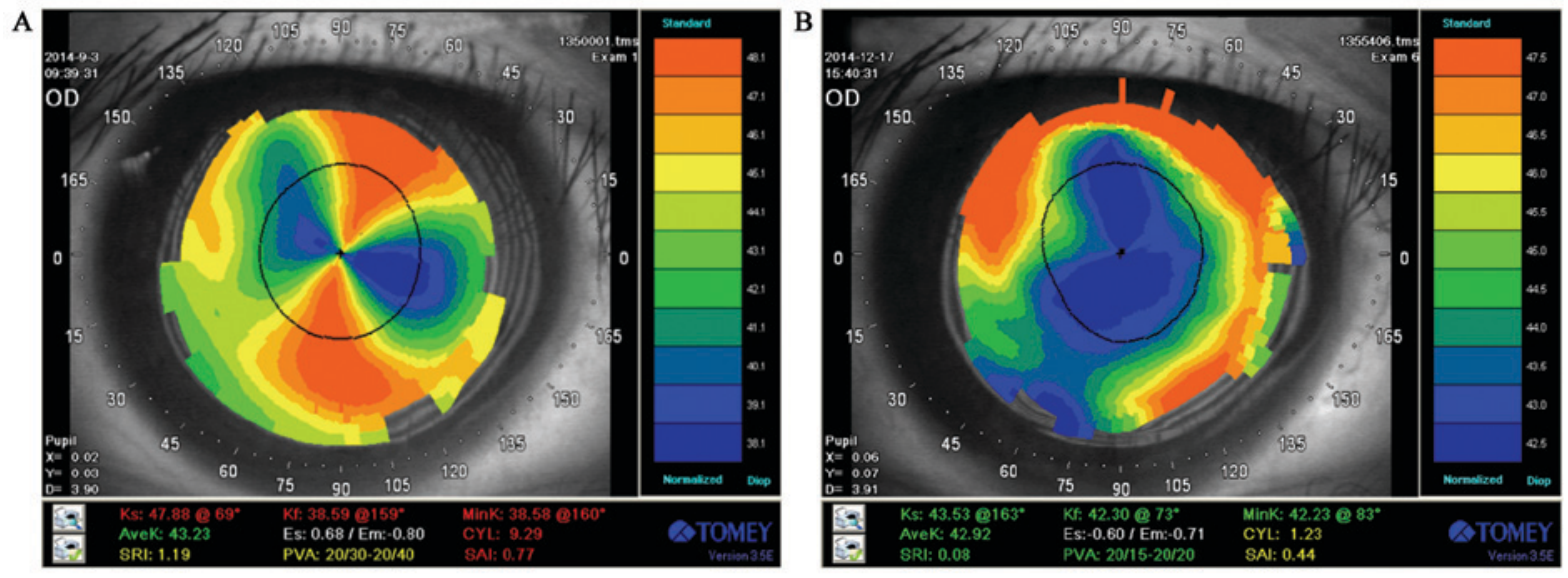

Figure 2. Corneal topography of a patient (A) prior to undergoing AK combined with scleral tunnel incisions and (B) at 3 months post-surgery. The black circular line represents the size of the pupil. An obvious decrease in keratometric astigmatism is apparent after AK combined with scleral tunnel incisions. AK, astigmatic keratotomy.

\section{Results}

Patient characteristics. The study included 8 patients (3 females and 5 males aged 21-56 years; mean age, $29.50 \pm 11.60$ years), who had a history of high residual astigmatism after PKP. The most common pre-operative diagnosis was keratoconus in 7 eyes, followed by infectious corneal scar in 1 eye. The mean interval between PKP and the surgical treatment was $17 \pm 5.5$ months. AK and scleral tunnel incision (case no. 1, male, 22 years old) was performed on the right eye of a patient to correct high astigmatism after penetrating keratoplasty (Fig. 1).

Visual acuity and refraction changes. The mean values for the visual acuity and refraction changes are presented in

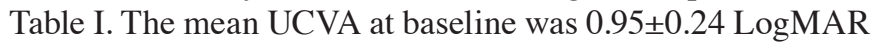
and that at 3 months post-surgery was $0.61 \pm 0.17$ LogMAR; this difference was statistically significant $(\mathrm{P}<0.05)$. Prior to surgery, the mean BCVA was $0.41 \pm 0.18 \operatorname{LogMAR}$ and that at
3 months post-surgery was $0.26 \pm 0.12 \log$ MAR; this change was not statistically significant $(\mathrm{P}>0.05)$. The mean magnitude of keratometric astigmatism was $8.16 \pm 3.02 \mathrm{D}$ pre-operatively and $2.28 \pm 1.07 \mathrm{D}$ at 3 months postoperatively; the mean difference resembled a reduction by $5.88 \mathrm{D}$, which was a significant change $(\mathrm{P}<0.05)$. The keratometric astigmatism could not be corrected significantly through the combined procedure in a patient (case no. 7 , female, 56 years old). The mean subjective astigmatism was $7.68 \pm 2.62 \mathrm{D}$ pre-operatively and $2.5 \pm 1.24 \mathrm{D}$ at 3 months postoperatively, with a statistically significant reduction by $5.18 \mathrm{D}(\mathrm{P}<0.05)$. The mean spherical equivalent refraction pre-operatively and at 3 months post-surgery was $3.65 \pm 1.05$ and $-3.38 \pm 0.97 \mathrm{D}$, respectively, and the difference was not statistically significant $(\mathrm{P}>0.05)$. The pre-operative and 3 month post-operative corneal topography in a patient (case no. 1, male, 22 years old) who had undergone AK combined with scleral tunnel incisions demonstrated a decrease in keratometric astigmatism from 9.29 to 1.23 D (Fig. 2). 
Table II. Individual KA assessed using vector analysis in cases 1-8.

\begin{tabular}{lccccccc}
\hline \multicolumn{7}{c}{ Parameters } \\
\cline { 2 - 8 } Case no. & TIA (D) & SIA (D) & DV (D) & AE $\left(^{\circ}\right)$ & ME (D) & IOS & Correction index \\
\hline 1 & 9.29 & 10.05 & 1.23 & 0 & -1.21 & 0.13 & 1.13 \\
2 & 7.38 & 4.02 & 3.42 & 2 & 3.36 & 0.46 & 0.54 \\
3 & 10.78 & 9.70 & 2.07 & 3 & -1.08 & 0.19 & 0.90 \\
4 & 5.63 & 7.92 & 2.29 & 0 & 2.29 & 0.40 & 1.41 \\
5 & 7.65 & 7.28 & 2.18 & 8 & -0.37 & 0.28 & 0.95 \\
6 & 5.70 & 3.77 & 2.13 & 5 & -1.93 & 0.37 & 0.59 \\
7 & 13.89 & 10.12 & 4.12 & -6 & -3.77 & 0.30 & 0.72 \\
8 & 5.02 & 4.60 & 0.83 & -5 & -0.42 & 0.17 & 0.92 \\
Mean & 8.16 & 7.18 & 2.28 & 3.5 & -1.80 & 0.29 & 0.90 \\
SD & 3.03 & 2.73 & 1.07 & 2.8 & 1.28 & 0.12 & 0.29 \\
\hline
\end{tabular}

KA, keratometric astigmatism; TIA, target induced astigmatism; D, diopters; SIA, surgically induced astigmatism; DV, difference vector; AE, angle of error; ME, magnitude of the error; IOS, index of success; SD, standard deviation.

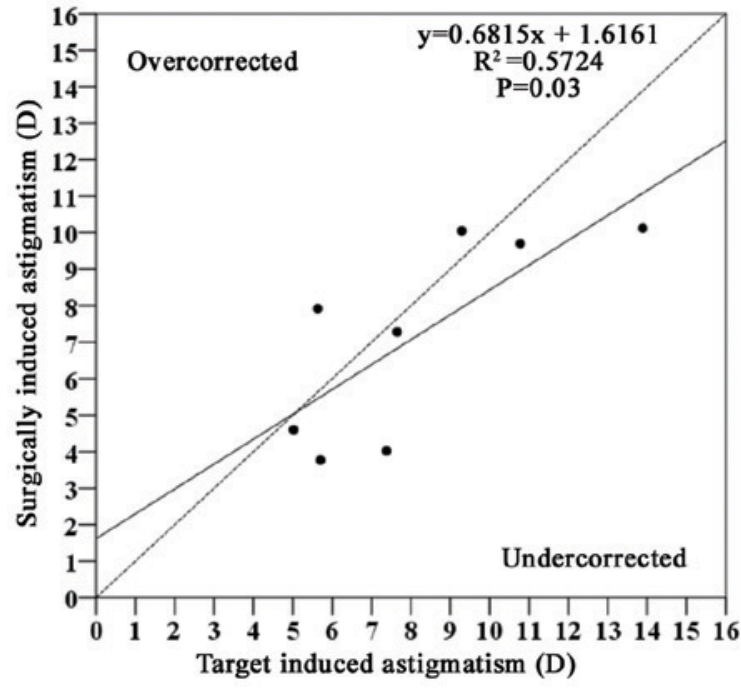

Figure 3. Correlation analysis of surgically induced astigmatism vs. target induced astigmatism. The solid line represents the linear regression of all treatments. The dotted line represents surgically induced astigmatism equal to the target induced astigmatism. There was a significant correlation between surgically induced astigmatism and target induced astigmatism $(\mathrm{r}=0.76, \mathrm{P}<0.05)$.

Vector analyses of keratometric astigmatism. The keratometric vectors were calculated for each eye (Table II). At 3 months postoperatively, the mean keratometric vectors were as follows: TIA, 8.17 \pm 3.03 ; SIA, 7.18 \pm 2.73 ; and DV, 2.28 \pm 1.07 . The mean AE was $3.5 \pm 2.82$, indicating no significant systematic bias. The mean ME was $-1.80 \pm 1.28$, suggesting a tendency for undercorrection. The correction index was $0.90 \pm 0.29$, again indicating a slight tendency for undercorrection. The IOS was $0.29 \pm 0.12$, suggesting a satisfying reduction of the original astigmatism. There was a significant correlation between SIA and the TIA $(\mathrm{P}<0.05$; Fig. 3$)$.

Stability. During the 6-month follow-up after AK combined with scleral tunnel incisions, the patients retained a stable

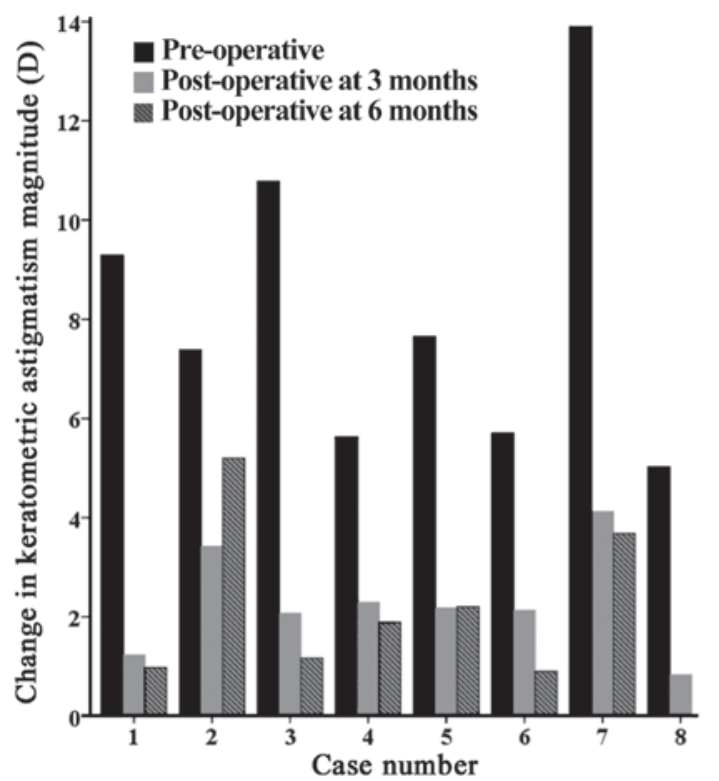

Figure 4. Change in keratometric astigmatism following AK combined with scleral tunnel incisions, at 3 and 6 months. Between 3 and 6 months after AK combined with scleral tunnel incisions, the keratometric astigmatism was stable. AK, astigmatic keratotomy.

keratometric astigmatism. At 3 and 6 months postoperatively, the mean keratometric astigmatism was $2.28 \pm 1.07$ and $2.02 \pm 1.69 \mathrm{D}$, respectively. There was no significant change in keratometric astigmatism at 3 and 6 months postoperatively $(\mathrm{P}=0.72$; Table III). In addition, a patient (case no. 8 , male, 28 years old) had zero post-operative astigmatism after 6 months (Fig. 4). The mean magnitude of SIA was 7.18 \pm 2.73 $\mathrm{D}$ at 3 months and $7.57 \pm 3.37 \mathrm{D}$ at 6 months $(\mathrm{P}=0.80$; Table IV). The mean difference in SIA magnitude between 3 months and 6 months also demonstrated no significant trend toward progression or regression.

Safety and complications. Patients were reviewed at 1 day, 1 week, 1, 3 and 6 months post-surgery and no severe 
Table III. Pre-operative and post-operative KA in cases 1-8.

\begin{tabular}{|c|c|c|c|c|}
\hline & $\begin{array}{c}\text { Pre- } \\
\text { operative }\end{array}$ & $\begin{array}{c}\text { Post- } \\
\text { operative } \\
3 \text { months }\end{array}$ & $\begin{array}{c}\text { Post- } \\
\text { operative } \\
6 \text { months }\end{array}$ & \\
\hline Case no. & KA (D) & KA (D) & KA (D) & P-value \\
\hline 1 & 9.29 & 1.23 & 0.98 & \\
\hline 2 & 7.38 & 3.42 & 5.20 & \\
\hline 3 & 10.78 & 2.07 & 1.17 & \\
\hline 4 & 5.63 & 2.29 & 1.89 & \\
\hline 5 & 7.65 & 2.18 & 2.20 & \\
\hline 6 & 5.70 & 2.13 & 0.90 & \\
\hline 7 & 13.89 & 4.12 & 3.68 & \\
\hline 8 & 5.02 & 0.83 & 0.00 & \\
\hline Mean \pm SD & $8.17 \pm 3.03$ & $2.28 \pm 1.07$ & $2.00 \pm 1.69$ & 0.72 \\
\hline
\end{tabular}

KA, keratometric astigmatism; D, diopters; SD, standard deviation.

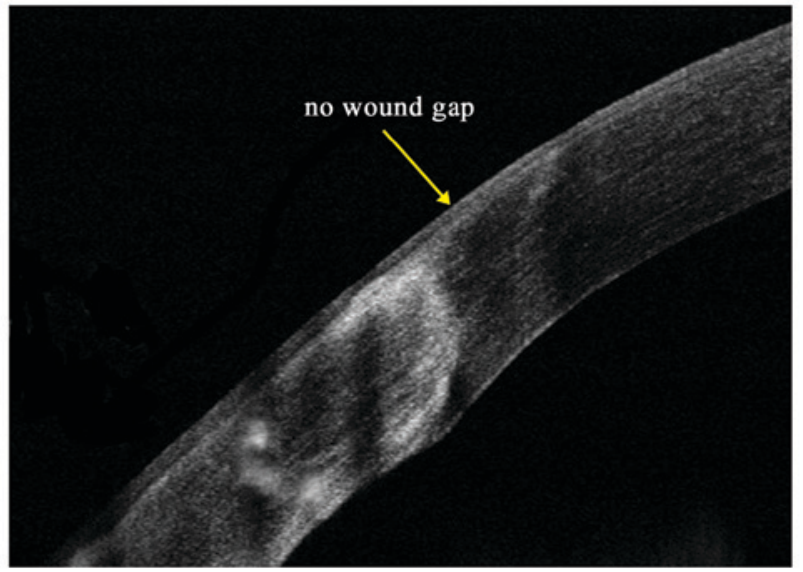

Figure 5. Representative case. The cross-sectional image obtained by optical coherence tomography indicates that there was no wound gap in the wound and the incision was healing well.

complications, including perforation or infectious keratitis, occurred in these patients. The Angio-OCT clearly displayed the morphology of the keratotomy incision. The cross-sectional image of the corneal incision (case no. 2, male, 27 years old), demonstrated no gaping of the wound (Fig. 5). The incisions were healing well in all patients.

\section{Discussion}

High residual astigmatism after PKP is a common complication due to various factors. Several studies have attempted to solve this problem with means including spectacles, AK, compression sutures, LASIK (8) and implantation of toric IOL. Although spectacles and contact lenses may correct refractive errors following PKP, it is difficult to correct high astigmatism after PKP using these methods (2). Wade et al (18) used a toric intraocular lens to correct astigmatism in 16 patients with prior PKP and reported a reduction in astigmatism from $3.34 \pm 2.13$ to $1.58 \pm 1.25 \mathrm{D}$. However, toric IOL implantation is
Table IV. Post-operative SIA in cases 1-8.

\begin{tabular}{lcccc}
\hline & $\begin{array}{c}\text { Post-operative } \\
3 \text { months }\end{array}$ & & $\begin{array}{c}\text { Post-operative } \\
6 \text { months }\end{array}$ & \\
\cline { 2 - 2 } Case no. & SIA (D) & & SIA (D) & P-value \\
\hline 1 & 10.05 & & 9.29 & \\
2 & 4.02 & & 3.72 & \\
3 & 9.70 & & 8.86 & \\
4 & 7.92 & & 7.96 & \\
5 & 7.28 & & 7.23 & \\
6 & 3.77 & & 4.70 & \\
7 & 10.12 & & 14.13 & \\
8 & 4.60 & & 4.67 & \\
Mean \pm SD & $7.18 \pm 2.73$ & $7.57 \pm 3.37$ & 0.80
\end{tabular}

SIA, surgically induced astigmatism; D, diopters; SD, standard deviation.

also limited by the range of astigmatism it is able to correct and it increases the risk for graft rejection after PKP (19).

Compared with other methods to correct astigmatism, AK has certain advantages, e.g., it is relatively simple and low-cost, and is commonly performed to correct astigmatism after PKP (15). Various different incision nomograms have been used in the AK procedure over the years $(3,4)$. The most common type of AK involves creating paired deep, curved corneal incisions at the steep astigmatism meridian. The fundamental principle of $\mathrm{AK}$ is that it relaxes the corneal tissue, thereby increasing the radius of curvature and flattening the steep meridian perpendicular to the incision. AK is also limited regarding the degree of astigmatism it is able to correct.

Scleral tunnel incisions are also able to flatten the corneal curvature when being placed at the steepest astigmatism meridian. Wirbelauer et al (20) used a 7-mm scleral tunnel incision centered at the steeper meridian to reduce pre-operative oblique astigmatism in subjects receiving cataract surgery and reported that a significant mean reduction in astigmatism of 0.58 $\mathrm{D}(\mathrm{P}<0.01)$ was achieved only in the group in which the incision was centered on the steeper meridian. Weindler et al (16) reported a reduction from 1.6 to $0.89 \mathrm{D}$ in astigmatism after using a scleral tunnel incision on the steepest meridian in cataract surgery. Heider et al (21) also reported that the technique of scleral tunnel incision on a steeper meridian reduced a pre-existing inverse or oblique astigmatism in cataract surgery.

Paired AK combined with scleral tunnel incisions is likely to produce a synergistic action and is expected to have an augmented effect in reducing high astigmatism after PKP. The effect of this combined method was evaluated in the present study.

Improvement of the UCVA and BCVA after the combined procedure was observed in the present study in comparison with the results of femtosecond laser-assisted AK for the treatment of high-astigmatism post-PKP reported by Cleary et al (22) and Fadlallah et al (23). In the present study, the mean UCVA improved from $0.95 \pm 0.24 \log$ MAR pre-operatively to $0.61 \pm 0.17 \log$ MAR postoperatively $(\mathrm{P}<0.05)$. The mean 
BCVA improved from $0.41 \pm 0.18$ LogMAR pre-operatively to $0.26 \pm 0.12 \operatorname{LogMAR}$ postoperatively $(\mathrm{P}>0.05)$. Although the change was not statistically significant, there was a trend toward improvement in the post-operative BCVA.

The mean pre-operative magnitude of keratometric astigmatism was $8.16 \pm 3.02 \mathrm{D}$, and at 3 months postoperatively, the mean keratometric astigmatism was $2.28 \pm 1.07 \mathrm{D}$, with a statistically significant reduction by $5.88 \mathrm{D}(\mathrm{P}<0.01)$. The mean pre-operative subjective astigmatism decreased from $7.68 \pm 2.62$ to $2.5 \pm 1.24 \mathrm{D}(\mathrm{P}<0.05)$. Compared with other current surgical treatments, including AK alone or LASIK, the combined surgical treatment produced a greater reduction in astigmatism. Böhringer et al (24) performed AK alone to correct keratometric astigmatism and reported a reduction in mean astigmatism from 9.2 to $5.5 \mathrm{D}$ after AK. Cleary et al (22) observed a decrease in keratometric astigmatism from 9.8 \pm 2.9 to $4.5 \pm 3.2 \mathrm{D}$ after femtosecond laser-assisted AK. Donnenfeld et al (25) used LASIK to correct astigmatism after PKP and reported a decrease in astigmatism from $3.64 \pm 1.72 \mathrm{D}$ pre-operatively to $1.29 \pm 1.04 \mathrm{D}$ postoperatively. Several combined surgery methods have been reported for the treatment of high astigmatism. The reduction in astigmatism achieved using the combined procedure of the present study is similar to or better than that achieved by other combined surgery methods. Sy et al (14) performed AK combined with conductive keratoplasty to treat high astigmatism and reported a reduction in astigmatism from $10.25 \pm 4.71$ to $4.31 \pm 2.34 \mathrm{D}$. Javadi et al (26) reported a relatively lesser reduction in astigmatism from $6.8 \pm 1.4$ to $3.9 \pm 1.6 \mathrm{D}$ after augmented relaxing corneal incisions. Of note, the combined procedure of the present study failed to significantly correct the keratometric astigmatism in 1 patient (case no. 7, female, 56 years old), who was the oldest in the study cohort; it may be assumed that the decline of corneal biomechanics with age is one of the major reasons. Day and Stevens (27) reported that the SIA is dependent on the biomechanical properties of the cornea. In the present study, the change in spherical equivalent refraction was not statistically significant $(\mathrm{P}>0.05)$.

On the basis of the keratometric data, the predictability of the new combined procedure was evaluated. Alpin's method was used in the present study, as the method is able to comprehensively analyze the changes of astigmatism (17). In the present study, the SIA was closely correlated with the TIA. The keratometric analysis indicated an undercorrection of the astigmatism in most cases. The negative ME values, which are obtained if the magnitude of the SIA is less than the magnitude of the TIA, also reflected a trend toward undercorrection. The mean correction index, which was $<1.0$ in the present study, also indicated undercorrection. These outcomes are similar to those obtained by Sy et al (14). The mean AE value was only $3.5 \pm 2.82$, indicating no systematic misalignment. The IOS, which is preferably 0 , was $0.29 \pm 0.12$ in the present study, and it testified the relative predictability of the novel combined method.

The stability profile was also assessed in the present study. There was no significant change in keratometric astigmatism between 3 and 6 months post-surgery. The change in the mean SIA between 3 and 6 months postoperatively also demonstrated no significant trend toward progression or regression.
The safety of an operation is another important issue. In the present study, no severe complications, including secondary glaucoma, infectious keratitis or perforation, were encountered in any of the patients. In addition, there was no implantation of epithelium of the cornea in the wounds. The Angio-OCT images demonstrated that there was no gaping in the wounds and incisions were healing well in all patients. It is therefore indicated that the treatment of AK combined with scleral tunnel incisions may be a safe method to reduce high astigmatism after PKP.

Based on previous studies, the effect of AK is affected by three factors: The length of the incision arc, the depth of the incision and the position of the incision. Increasing the length of the incision arc may yield better results. Kumar et al (28) performed intralase-enabled AK to correct high astigmatism after PKP. The depth of the incision was set at $90 \%$ and it was placed $0.50 \mathrm{~mm}$ inside the graft. The length of the incision arc was determined by the magnitude of the astigmatism: $40-60^{\circ}$ for up to $6 \mathrm{D}, 65-75^{\circ}$ for $6-10 \mathrm{D}$ and $90^{\circ}$ for $>10 \mathrm{D}$ of astigmatism. They obtained a reduction in astigmatism by $64 \%$. Fares et al (29) also applied a varied incision depth according to the magnitude of astigmatism to correct astigmatism after PKP and reported a satisfactory reduction in astigmatism. Increasing the depth of the incision is another option. Akura et al (30) reported a method of AK termed full-arc, depth-dependent AK (FDAK). They chose an arcuate incision of $90^{\circ}$ in length with an optical zone of $7.0 \mathrm{~mm}$ and varied the incision depth between 40 and $75 \%$ to treat astigmatism; the outcomes demonstrated that FDAK may be an effective and safe method to correct astigmatism. In addition, incision nomograms may also be affected by changes in optical zone size, with a small optical zone having a greater effect. However, as the cornea becomes thin near its center, the difficulty of the surgery is increased. Based on previous studies, the use of the following incision nomogram may be proposed: All incisions should be placed at $7.0 \mathrm{~mm}$ into the optical zone and have a depth of $90 \%$ of the cornea. The Arc length should range from 60 to $85^{\circ}$, with $60-65^{\circ}$ for 5-6 D, $65-75^{\circ}$ for 7-10 D and $85^{\circ}$ for $>10 \mathrm{D}$ of astigmatism (28-30).

In conclusion, AK combined with scleral tunnel incisions is an effective, relatively predictable and safe method to reduce high astigmatism after PKP. The limitations of the present study include the small number of subjects and the limited follow-up time. An increase of sample size and long-term observation are required to further examine the efficacy of the combined procedure. In addition, further studies are required to improve the incision nomograms for improving the predictability of this combined procedure.

\section{Acknowledgements}

Not applicable.

\section{Funding}

The project was supported by the Science Foundation of Anhui Medical University (grant no. 2017kj25).

\section{Availability of data and materials}

The datasets used and/or analyzed during the current study are available from the corresponding author on reasonable request. 


\section{Authors' contributions}

Z-YG designed the study and performed patient examinations; M-JY and K-KJ collected and analyzed the data; Z-YG and R-FL prepared the manuscript; R-FL performed the surgeries and supervised the project. All authors read and approved the final manuscript.

\section{Ethics approval and consent to participate}

The present study was approved by the Ethics Committee of the First Affiliated Hospital of Anhui Medical University (reference no. Quick-PJ 2013-11-17). Informed consent was obtained from all participants.

\section{Patient consent for publication}

Patients provided written informed consent for publication.

\section{Competing interests}

The authors declare that they have no competing interests.

\section{References}

1. Williams KA, Roder D, Esterman A, Muehlberg SM and Coster DJ: Factors predictive of corneal graft survival. Report from the Australian Corneal Graft Registry. Ophthalmology 99: 403-414, 1992.

2. Bochmann F and Schipper I: Correction of post-keratoplasty astigmatism with keratotomies in the host cornea. J Cataract Refract Surg 32: 923-928, 2006.

3. Nubile M, Carpineto P, Lanzini M, Calienno R, Agnifili L, Ciancaglini $\mathrm{M}$ and Mastropasqua L: Femtosecond laser arcuate keratotomy for the correction of high astigmatism after keratoplasty. Ophthalmology 116: 1083-1092, 2009.

4. Kim BK, Mun SJ, Lee DG, Kim JR, Kim HS and Chung YT: Full-thickness astigmatic keratotomy combined with small-incision lenticule extraction to treat high-level and mixed astigmatism. Cornea 34: 1582-1587, 2015.

5. Fronterrè $A$ and Portesani GP: Relaxing incisions for postkeratoplasty astigmatism. Cornea 10: 305-311, 1991.

6. Ezra DG, Hay-Smith G, Mearza A and Falcon MG: Corneal wedge excision in the treatment of high astigmatism after penetrating keratoplasty. Cornea 26: 819-825, 2007.

7. Chang SM, Su CY and Lin CP: Correction of astigmatism after penetrating keratoplasty by relaxing incision with compression suture: A comparison between the guiding effect of photokeratoscope and of computer-assisted videokeratography. Cornea 22: 393-398, 2003

8. Arenas E and Maglione A: Laser in situ keratomileusis for astigmatism and myopia after penetrating keratoplasty. J Refract Surg 13: 27-32, 1997.

9. de Sanctis U, Eandi C and Grignolo F: Phacoemulsification and customized toric intraocular lens implantation in eyes with cataract and high astigmatism after penetrating keratoplasty. J Cataract Refract Surg 37: 781-785, 2011

10. Akcay L, Kaplan AT, Kandemir B, Gunaydin NT and Dogan OK: Toric intraocular Collamer lens for high myopic astigmatism after penetrating keratoplasty. J Cataract Refract Surg 35: 2161-2163, 2009.

11. Wang J, Zhao J, Xu J and Zhang J: Evaluation of the effectiveness of combined femtosecond laser-assisted cataract surgery and femtosecond laser astigmatic keratotomy in improving post-operative visual outcomes. BMC Ophthalmol 18: 161, 2018.
12. Buzzonetti L, Petrocelli G, Laborante A, Mazzilli E, Gaspari M and Valente P: Arcuate keratotomy for high postoperative keratoplasty astigmatism performed with the intralase femtosecond laser. J Refract Surg 25: 709-714, 2009.

13. Çakır H, Genç S and Güler E: Circular keratotomy combined with wedge resection in the management of high astigmatism after penetrating keratoplasty. Eye Contact Lens: 25 June, 2018 (Epub ahead of print).

14. Sy ME, Kovoor TA, Tannan A, Choi D, Deng SX, Danesh J and Hamilton DR: Combined astigmatic keratotomy and conductive keratoplasty to correct high corneal astigmatism. J Cataract Refract Surg 41: 1050-1056, 2015.

15. Wilkins MR, Mehta JS and Larkin DF: Standardized arcuate keratotomy for postkeratoplasty astigmatism. J Cataract Refract Surg 31: 297-301, 2005.

16. Weindler J, Pesch C, Hille K and Ruprecht KW: Lateral corneoscleral 6-mm-incision for reduction of against-the-rule astigmatism. Eur J Implant Ref Surg 7: 244-246, 1995.

17. Bachernegg A, Rückl T, Strohmaier C, Jell G, Grabner G and Dexl AK: Vector analysis, rotational stability, and visual outcome after implantation of a new aspheric toric IOL. J Refract Surg 31: 513-520, 2015.

18. Wade M, Steinert RF, Garg S, Farid M and Gaster R: Results of toric intraocular lenses for post-penetrating keratoplasty astigmatism. Ophthalmology 121: 771-777, 2014.

19. Iovieno A, Guglielmetti S, Capuano V, Allan BD and Maurino V: Correction of postkeratoplasty ametropia in keratoconus patients using a toric implantable Collamer lens. Eur J Ophthalmol 23: 361-367, 2013.

20. Wirbelauer C, Anders N, Pham DT and Wollensak J: Effect of incision location on preoperative oblique astigmatism after scleral tunnel incision. J Cataract Refract Surg 23: 365-371, 1997.

21. Heider W, Müller M, Schalnus R and Kaiser P: Corneal topography after cataract surgery with tunnel incision on a steeper meridian in inverse and oblique astigmatism. Ophthalmologe 94: 16-19, 1997 (In German).

22. Cleary C, Tang M, Ahmed H, Fox M and Huang D: Beveled femtosecond laser astigmatic keratotomy for the treatment of high astigmatism post-penetrating keratoplasty. Cornea 32: 54-62, 2013.

23. Fadlallah A, Mehanna C, Saragoussi JJ, Chelala E, Amari B and Legeais JM: Safety and efficacy of femtosecond laser-assisted arcuate keratotomy to treat irregular astigmatism after penetrating keratoplasty. J Cataract Refract Surg 41: 1168-1175, 2015.

24. Böhringer D, Dineva N, Maier P, Birnbaum F, Kirschkamp T, Reinhard $\mathrm{T}$ and Eberwein P: Long-term follow-up of astigmatic keratotomy for corneal astigmatism after penetrating keratoplasty. Acta Ophthalmol 94: e607-e611, 2016.

25. Donnenfeld ED, Kornstein HS, Amin A, Speaker MD, Seedor JA, Sforza PD, Landrio LM and Perry HD: Laser in situ keratomileusis for correction of myopia and astigmatism after penetrating keratoplasty. Ophthalmology 106: 1966-1975, 1999.

26. Javadi MA, Feizi S, Yazdani S, Sharifi A and Sajjadi H: Outcomes of augmented relaxing incisions for postpenetrating keratoplasty astigmatism in keratoconus. Cornea 28: 280-284, 2009.

27. Day AC and Stevens JD: Predictors of femtosecond laser intrastromal astigmatic keratotomy efficacy for astigmatism management in cataract surgery. J Cataract Refract Surg 42: 251-257, 2016.

28. Kumar NL, Kaiserman I, Shehadeh-Mashor R, Sansanayudh W, Ritenour R and Rootman DS: IntraLase-enabled astigmatic keratotomy for post-keratoplasty astigmatism: on-axis vector analysis. Ophthalmology 117: 1228-1235.e1, 2010.

29. Fares U, Mokashi AA, Al-Aqaba MA, Otri AM, Miri A and Dua HS: Management of postkeratoplasty astigmatism by paired arcuate incisions with compression sutures. Br J Ophthalmol 97: 438-443, 2013

30. Akura J, Matsuura K, Hatta S, Kaneda S and Kadonosono K: Clinical application of full-arc, depth-dependent, astigmatic keratotomy. Cornea 20: 839-843, 2001. 